+1032 DETECTION OF DONOR'S LYMPHOCYTES IN THE PERIPHERAL BLOOD OF NEONATES FOLLOWING EXCHANGE-TRANSFUSION. M.Xanthou, H.Mandyla, M.Berietou and C.Metaxotou Medical School of Athens University "Aghia Sophia"Children's Hospital 1st Dept of Pediatrics-Neonatal Intensive Care Unit. Twenty preterm and term female neonates were exchange-transfused with males donor fresh blood during their first days of life because of hyperbilirubinaemia or severe septicaemia. In or der to study the presence of donor lymphocytes in the neonates peripheral blood, chromosome studies were performed immediately after, 12 and 72 hours following the exchange transfusion. We used the fluorescent-binding technique in order to distinguish the donor's cells by the presence of the Y-chromosone or other fluorescent markers in at least 300 mitotic figures in each speciment. We found that in jaundiced babies immediately following exchange transfusion less than $10 \%$ of the lymphocytes came from the donor and 12 hours later only $1-2 \%$ were still present. However in neonates exchange-transfusion for septicaemia the percentage of donor's lymphocytes immediately following the proceedure sometimes reached $50 \%$ and dropped to less than $10 \%$ by 12 hours. This shows the inability of the depressed by the infection host defence mechanisms of the newborn to deal with the donor's lymphocytes.

\section{+10 POLYMORPHONUCLEAR LEUKOCYTE SUPEROXIDE $\uparrow 1033$ ANION GENERATION IN CRITICALLY ILL CHILDREN} Shelhamer. Div of Intensive Care, Depts of Anesth, Pediatr, Geo Wash Univ Sch Med, Child Hosp Nat'l Med Ctr, Wash., D.C. and NIH Clin Ctr, Beth., MD (Spon by Glenn Rosenquist).

Generation of active oxygen species by activated PMNs plays a paramont role in human immunologic defenses. However, numerous in vitro experiments have demonstrated that inadvertant release of highly reactive oxygen metabolites by the PMN into the surrounding milieu reactive oxygen metabolites by the PMN into the surrounding milieu
results in autoinjury and is associated with diffuse capillary leak results in autoinjury and is associated with diffuse capillary leak
syndromes (septic shock, ARDS). NADPH oxidoreductase, the syndromes (septic shock, ARDS). NADPH oxidoreductase, the
superoxide anion generating enzyme, is a PMN membrane bound flavoprotein normally dormant but inducible by a variety of agents. We studied the specific activity of this enzyme in criticelly ill children to determine if detection of th activation might provide an children to impending in inflammatory amplification injury. Venous blood specimens from 12. healthy young adult controls reflected an induced enzyme activity of $8.23 \pm 2.1$ nmoles superoxide/min. $/ 10^{6} \mathrm{PMNs} \pm$ S.D. Similarly the induced activity in a group of 6 pediatric intensive care patients without evidence of capillary leak syndrome was $7.3 \pm 2.2$. In constrast the mean induced activity from a group of 6 critically ill children with evidence of capillary leak syndrome was $3.0+1.1(p<.001)$. No activity was demonstrated in non-induced PMNs from any group. No differences in induced enzyme activity were appreciated between venous and arterial blood samples. Such findings may demonstrate the phenomena of desensitization of previously in vivo activated neutrophils to of desensitization of previously in vivo activated neutrophils to
additional stimulation, and may represent a host defense which additional stimulation,
minimizes autoinjury.

\section{INFECTIOUS DISEASES}

1034

the PREVAlence of Cytomegalovirus (CMV) Wilson Adler, Linda T. Lawrence, and Mary S. Virson. (Spon. by H. Maurer) Medical College of In 17 months 2198 children had, Richmond

In 17 months 2198 children had admission urines cultured for CMV. $4.7 \%$ had CMV Viruria ( 105 positive cultures), but significant age differences were observed. In the intensive care nursery the prevalence of CMV viruria (congenital and acquired infections) was $3.3 \%$ ( 18 of 551 newborns with viruria). On the nursing units for children ages 0 to 2 yrs, the prevalence of CMV viruria was $6.8 \%$ ( 32 of 544 positive, $\mathrm{P}<0.01$, Chi square $=7.3$, when compared to newborns). The prevalence of CMV viruria on a nursing unit for children ages 2 to 5 yrs was $7.2 \%$ ( 27 of $382)$, similar to that for children 0 to 2 yrs $\quad(P>0.5$ chi square $=0.004)$. On a nursing unit for children ages 5 to 12 yrs the prevalence of CMV viruria decreased to $4.2 \%$ ( 20 of $476, P=0.01$, Chi square $=6.6$ when compared to children 2 to 5 yrs). For 12 to 18 year olds the prevalence of CMV viruria was only $1.2 \%$ ( 3 of 245 , $P<.001$, Chi square $=9.2$, when compared to children 5 to $12 \mathrm{yrs}$ ). Among 72 seronegative nurses with daily patient contact, none acquired CMV but only 20 worked with the high prevalence age group ( 0 to 5 yrs). These results suggest that in spite of constant exposure CMV transmission occurs infrequently.
1035 THE EFFect of Gestational, AgE AND LABOR UPON INTRACELLULAR SURVIVAL OF HERPES SIMPLEX VIRUS (HSV). Fred G. Smith, Jr.), Univ. of lowa College of Medicine, Dept. of Pediatrics, Iowa City. Neonatal HSV infection is often characterized by rapid, life-threatening dissemination. Perinatal immunologic factors examined to date incompletely account for this tendency to disseminate, for the rapid disappearance of this vulnerability early in postnatal life, and for the disproportionate occurrence in prematures. To determine a possible influence of gestational age or perinatal events upon this phenomenon, we studied 29 placental specimens of varying gestational age and mode of delivery. The intracellular survival of type 2 HSV within placental lymphocytes was assessed at 48 hour intervals for 6 days to determine the frequency and magnitude of virus titer changes. Early (0-48hrs) titer increases were significantly $(\mathrm{p}=0.015)$ more frequent in specimens with gestational age $\leq 35$ wks $(3 / 8)$ than those with $\geq 36$ wks $(0 / 21)$ gestations. Titer increase from 48 to 96 hours were common (14/29) but bore no relationship to gestational age, labor, or mode of delivery. Most importantly, late $(>96 \mathrm{hrs})$ titer increases were most influenced by the occurrence of labor and unrelated to gestational age. Late titer increases did not occur in specimens from caesarian section without labor $(0 / 12)$ and were significantly $(\mathrm{p}=0.023)$ more frequent in specimens where labor occurred (7/17). These findings are consistent with the hypothesis that early gestational age and the occurrence of labor transiently provide a more permissive intracellular environment for HSV replication and dissemination.

CEFOTAXIME IN THE TREATMENT OF BACTERTAL MENINGITIS $1036 \frac{\text { Basim I. Asmax }}{\text { Denise M. Kobos, }}, \frac{\text { M.C. Thirumoorthi, Joyce A. Buckley, }}{\text { and Adnan S. Dajani. Wayne State }}$ Univ. and Children's Hospital of Michigan, Detroit, Michigan. we evaluated the efficacy of cefotaxime in the treatment of bacterial meningitis and the diffusion of the drug into CSF. Eleven children ( 9 days to $5 \mathrm{yrs}$ ) with meningitis due to $\mathrm{H}$. influenzae $\left(7\right.$ cases), $\underline{s}$. pneumoniae(2), group B streptococcus $(\overline{1}), \frac{\text { influ }}{\text { and }}$ Salmonella sp. (1), were treated with $40 \mathrm{mg} / \mathrm{kg}$ of IV cefotaxime q6hrs. Cefotaxime levels were determined by HPLC. The mean cefotaxime plasma level $3 \mathrm{hrs}$ after a dose early in the treatment was $14.1 \mathrm{mg} / \mathrm{L}$ (range $5.1-42.2 \mathrm{mg} / \mathrm{L}$ ), and the mean CSF level was $3.9 \mathrm{mg} / \mathrm{L}(0.7-16.6 \mathrm{mg} / \mathrm{L})$. The mean CSF diffusion rate was 26.48 . At the end of treatment, the mean plasma level was $7.9 \mathrm{mg} / \mathrm{L} / 1.5-$ $13.6 \mathrm{mg} / \mathrm{L})$ and the mean CSF level was $1.23 \mathrm{mg} / \mathrm{L}(0.5-3.1 \mathrm{mg} / \mathrm{L})$ representing a mean diffusion rate of 21.98 . Cefotaxime MBC for the infecting organisms ranged between $0.015 \mathrm{mg} / \mathrm{L}$ and $0.25 \mathrm{mg} / \mathrm{L}$. CSF was bactericidal to the infecting organisms at dilutions between 8 and 256. The CSF diffusion correlated positively with the cefotaxime plasma level $(r=0.86)$, CSF protein $(r=0.63)$, CSF leukocyte count $(r=0.61)$ and negatively with CSF sugar $(r=-0.37)$. All patients responded well to treatment with no apparent sequelae.

Serial levels were also determined in 5 infants with ventriculostomies. Following a single dose of $40 \mathrm{mg} / \mathrm{kg}$, the mean cefotaxime CSF levels (and mean plasma levels) were $6.6 \mathrm{mg} / \mathrm{L}(28.4$ $\mathrm{mg} / \mathrm{L})$ at $2 \mathrm{hrs}, 5.7 \mathrm{mg} / \mathrm{L}(8.9 \mathrm{mg} / \mathrm{L})$ at $4 \mathrm{hrs}$, and $4.5 \mathrm{mg} / \mathrm{L}$ $(1.8 \mathrm{mg} / \mathrm{L})$ at $6 \mathrm{hrs}$. Cefotaxime diffuses sufficiently and consistently into CSF. Further assessment of its efficacy in the treatment of childhood meningitis is warranted.

1037 LEukocytes. James F. Bale, Jr. and Marsha $\mathrm{O}^{\prime} \mathrm{Neil}$ College of Medicine, Department of Pediatrics, Iowa City, Iowa. Cytomegalovirus (CMV) infections have been associated with altered host defense and increased susceptibility to secondary infection. In previous experiments, we observed impaired migratory and chemotactic activity of neutrophils harvested from mice during sublethal murine CMV (MCMV) infection. To investigate further the effects of CMV infection upon phagocytic leukocytes, we incubated murine leukocyte suspensions (95\% neutrophils) in vitro with MCMV derived either from tissue culture passage or salivary gland homogenate. Neutrophils incubated with salivary gland MCMV had depressed chemotactic activity at 2 and $4 \mathrm{~h}$. For example, at $4 \mathrm{~h}$ the mean chemotactic index of neutrophils incubated with MCMV was 0.92 vs 2.56 in controls ( $p \times 0.01)$. Phagobated with MCMV was 0.92 vs 2.56 in controls $(p \times 0.01)$. Phago-
cytic activity at $4 \mathrm{~h}$ was also reduced (mean of 1.53 latex particies/cell in MCMV-incubated vs 2.39 in controls, p<0.01). In contrast, tissue culture-passed MCMV did not alter leukocyte function. Adherence of MCMV to phagocytic leukocytes was comparable to adherence of virus to mouse embryo fibroblast cells ( 2 to $3 \mathrm{log}$ plaque forming units of MCMV/106 cells). Transmission electron microscopy at $4 \mathrm{~h}$ demonstrated occasional intracytoplasmic virions. These results indicate that impaired chemotactic and phagocytic activity of phagocytic leukocytes occurs after in vitro incubation with salivary gland-derived MCMV but. not with tissue culture-passed virus. These differences may be attributable to altered virulence of MCMV or to the presence of soluble factors in salivary gland MCMV pools 